\title{
ANÁLISE HISTOLÓGICA DOS FERRÕES DE RAIAS NO MUNICÍPIO DE SOURE/ILHA DO MARAJÓ - PARÁ
}

\section{ARTIGO ORIGINAL}

SANTOS, Adna Keila dos ${ }^{1}$

GEMAQUE, Rodrigo Sena ${ }^{2}$

BIANCALANA, Fernanda Simas Corrêa ${ }^{3}$

BIANCALANA, Adriano 4

SANTOS, Adna Keila dos. Et al. Análise histológica dos ferrões de raias no Município de Soure/llha Do Marajó - Pará. Revista Científica Multidisciplinar Núcleo do Conhecimento. Ano 05, Ed. 10, Vol. 08, pp. 141-157. Outubro de 2020. ISSN: 24480959, Link de acesso: https://www.nucleodoconhecimento.com.br/biologia/analisehistologica

\section{RESUMO}

As raias são animais de grande distribuição e quando pisoteadas ocasionam graves acidentes. Esses animais possuem importantes representantes como a família Dasyatidae e a Potamotrygonidae sendo essa última pertencente ao ambiente dulcícola. No município de Soure na ilha de Marajó todos os anos há registros dos acidentes com esses animais, desse modo se faz necessário analisar a morfologia

\footnotetext{
${ }^{1}$ Graduanda em Ciências Biológicas pela Universidade Federal do Pará - UFPA.

${ }^{2}$ Graduando em Ciências Biológicas pela Universidade Federal do Pará - UFPA.

${ }^{3}$ Doutora em Ciências Médicas pela Universidade Estadual de Campinas, Brasil (2011). Mestre em Ciências Médicas pela Universidade Estadual de Campinas, Brasil (2007).

${ }^{4}$ Doutor em Biologia Celular e Estrutural pela Universidade Estadual de Campinas, Brasil (2009).
} 
dos ferrões das raias e comparar entre as espécies capturadas no município. Para isso os aguilhões foram removidos das espécies durante a pesca artesanal no município e fixados em formalina $10 \%$. Posteriormente descalcificados em solução contendo EDTA 5\% para realização dos procedimentos histológicos, que envolvem inclusão em parafina histológica, corte dos blocos e colorações especificas para serem analisados no microscópio de luz. Através das analises microscópicas as espécies Dasiatis guttata, Potamotrygon orbgnyi, Potamotrygon scobina e Plesiotrygon iwamae apresentaram ferrão com organização celular semelhante, no entanto as células secretoras de veneno estavam presentes em regiões diferentes do epitélio de espécies dulcícolas em relação a animais marinhos, além do mais, o tecido epitelial apresentou constituição frágil podendo maximizar a gravidade dos acidentes e ainda foi possível visualizar uma conexão entre a região óssea e o tecido conjuntivo sendo que na região óssea foi possível observar a presença de vasos. Dessa forma estudos de caracterização dos ferrões são importantes, pois auxiliam no entendimento a respeito dos mecanismos de defesa desses animais.

Palavras-chave: Água doce, marinha, ictismo, veneno, morfologia.

\section{INTRODUÇÃO}

As raias são animais venenosos que estão relacionados a muitos acidentes com seres humanos (GARRONE NETO e HADDAD, 2010; SAMPAIO, 2014). Esses animais possuem grande distribuição, às marinhas por exemplo, da família Dasyatidae, podem ocorrer em toda a costa Brasileira, já a família Potamotrygonidae pertence exclusivamente ao ambiente dulcícola e pode ser encontrada na maior parte dos sistemas fluviais da América do Sul tropical (ROSA, 1985).

Os animais da família Potamotrygonidae, são exclusivamente de água doce, mas já pertenceram ao ambiente marinho durante o processo evolutivo e ao gênero Himantura (família Dasyatidae) aproximadamente 20 milhões de anos atrás, no Mioceno (LOVEJOY, 1996). Contudo em águas da América do sul, a família Potamotrygonidae, desenvolveu adaptações osmóticas e hoje vivem em ambientes dulcícolas (THORSON, 1967). 
É frequente a ocorrência de acidentes envolvendo esses animais nos rios da bacia amazônica e esse é um dos principais motivos pelo qual esses animais são temidos (CHARVET-ALMEIDA et al., 2002; CARVALHO et al., 2003). Por possuírem o habito bentônico se enterram no substrato e ao serem pisados na região dorsal giram a cauda que contem o ferrão em direção ao agressor introduzindo o aguilhão (SAMPAIO, 2014).

Os acidentes provocados por peixes recebem o nome de Ictismo que pode ser sarcotóxico, isto é, através da ingestão de toxinas presentes em órgãos e no próprio tegumento dos animais ou acantotóxico quando é através da mordida ou ferroada, sendo esse último mecanismo utilizado por raias (FUNASA, 2001).

A ferrada provoca intensa ação inflamatória (ANTONIAZZI et al., 2011). Provavelmente isto ocorra porque as raias possuem ferrões que são pequenas estruturas dérmicas que contem serrilhas nas laterais e estes estão localizados na região dorsal da cauda. $O$ aguilhão ainda possui um sulco glandular contendo células de veneno presente na região interna das laterais (CARVALHO et al., 2003).

Existem poucos trabalhos de descrição do aguilhão de raias apesar dos inúmeros acidentes ocasionados por esses animais, diante disso, o objetivo desta pesquisa é analisar a morfologia do ferrão e comparar entre as espécies capturadas no município de Soure na llha de Marajó localizado no estado do Pará no Brasil.

\section{METODOLOGIA}

\subsection{OBTENÇÕES DE AMOSTRAS BIOLÓGICAS}

Os ferrões foram coletados de três amostras diferentes das espécies: Potamotrygon scobina, Potamotrygon orbignyi, Plesiotrygon iwamae pertencentes a família Potamotrigonidae e Dasyatis guttata, único representante da família Dasyatidae no presente trabalho, no município de Soure (S0044'32,4";W048 $\left.30^{\prime 2} 24,9^{\prime \prime}\right)$ PA. (Sob licença fornecida pelo sistema sisbio/icmbio $n^{\circ}$ 60966-1) por meio de uma armadilha fixa chamada "Curral" (Figura 1). 
Figura 1: Curral. A) foto de um curral na área de estudo. B) esquema de como é um curral.

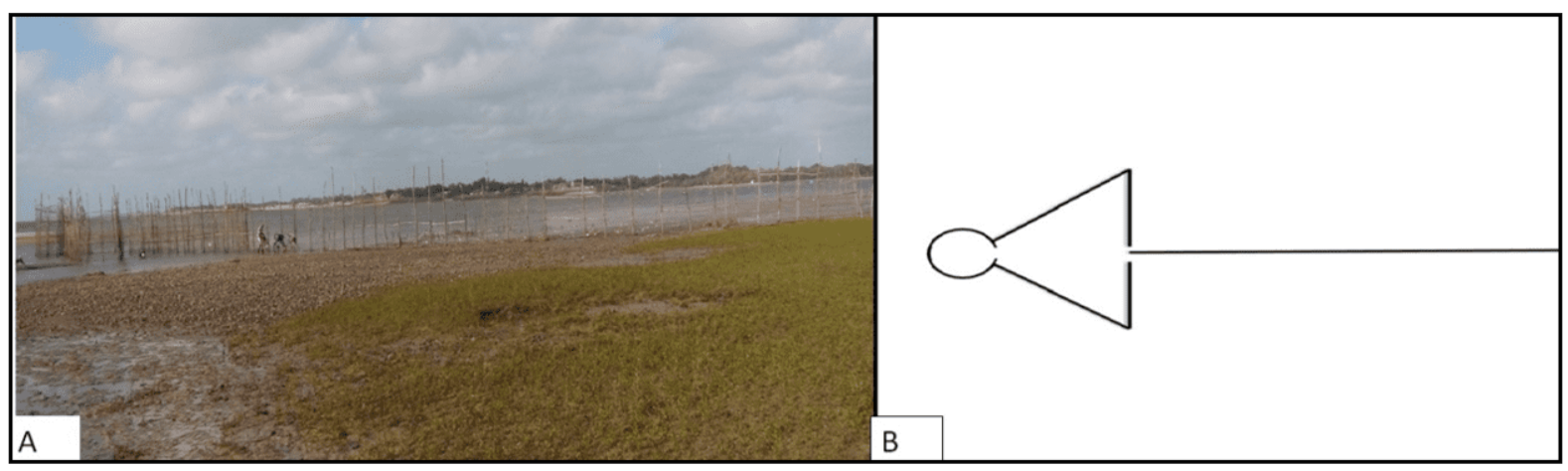

Fonte: autoria própria.

Os animais foram identificados através do uso de chaves taxonômicas baseadas em informações morfológicas (LASSO et al., 2013; GOMES et al., 2010).

\subsection{HISTOLOGIA}

Após a coleta as amostras foram fixadas em solução contendo formol 10\% e levados ao laboratório de biologia celular e molecular da Universidade federal do Pará. Depois de $24 \mathrm{~h}$ no fixador o material foi submetido ao processo de descalcificação em EDTA $5 \%$. O ferrão foi fragmentado e a região apical foi desidratada e embebida em parafina histológica na orientação transversal (PEDROSO et al., 2007) para produzir blocos que posteriormente foram cortados em fitas com auxilio de um micrótomo manual. Após isso, o material foi corado e analisado no microscópio óptico (Figura 2).

\subsection{HISTOQUÍMICA}

Os cortes foram submetidos às colorações Hematoxilina/Eosina para visão generalizada do tecido, Xylidine Ponceau para verificar a presença de proteínas totais e azul de Toluidina para análise de açúcares ácidos presentes nas células. 


\subsection{FOTOMICROGRAFIA}

As micrografias foram obtidas a partir de um microscópio óptico Nikon (eclipse E200) equipado com uma câmera digital e software de análise S-EYE (v. 1.3.2.297) (Figura 2D).

\subsection{COLETA DE DADOS SOBRE ACIDENTES COM RAIAS}

As informações a respeito do número de acidentes com raias no município de Soure foram fornecidas pelo Hospital Municipal “Menino Deus” no ano de 2018.

\section{RESULTADOS}

Nossos resultados sugerem que quatro espécies diferentes ocorrem na área de estudo três espécies pertencentes ao ambiente de água doce e uma única espécie marinha.

De acordo com o levantamento feito no hospital municipal a respeito dos acidentes com esses animais foram registrados noventa e três acidente somente no ano de 2018.

\subsection{HISTOLOGIA GERAL}

Os resultados mostraram que a estrutura do ferrão da espécie marinha Dasyatis guttata (Figura 2A) é composta por uma região óssea localizada no centro do ferrão, ao redor é encontrado o tecido conjuntivo e mais externamente uma cobertura de tecido epitelial (Figura 2B).

No epitélio estão presentes as células secretoras de veneno (Figura 2C-D), que costumam se localizar próximas às serras laterais essas células possuem vesículas fusiformes em seu citoplasma e são compostas por material proteico (Figura 2C).

As outras células epiteliais têm um formato arredondado, células glandulares é outro tipo de célula presente no epitélio (Figura 2E). 
Observou-se que tanto o epitélio dos animais marinhos quanto os de água doce são frágeis, pois na maioria das coletas de campo os ferrões não apresentaram tecido totalmente preservado e quando manuseados desprendem-se facilmente. Nas seções histológicas dessas regiões observou-se que em áreas onde não havia epitélio o tecido conjuntivo estava fortemente conectado ao osso (Figura $2 \mathrm{~F}$ ), além disso, a estrutura óssea parece ser bastante vascularizada (Figura $2 \mathrm{G}$ ). 
Figura 2. Fotomicrografia da estrutura morfológica do ferrão de Dasyatis guttata. A) Imagem da espécie Dasyatis guttata. B) Corte transversal do ferrão indicando a localização das células secretoras de veneno (seta) no tecido epitelial (TE). Tecido conjuntivo (TC) e região mineralizada (RM). Hematoxilina e Eosina. C) Maior aumento do epitélio evidenciando as células secretoras de veneno (CS) e as suas vesículas (seta). Células epiteliais (CE). Xylidine Ponceau. D) Maior aumento do epitélio evidenciando as células secretoras de veneno (CS) e as suas vesículas (seta). Células epiteliais (CE). Azul de Toluidina. E) Corte evidenciando as células glandulares (CG) e as células epiteliais (CE). Hematoxilina e Eosina. F) Região mineralizada (RM) com Vasos sanguíneos (V). Hematoxilina e Eosina. G) corte histológico que mostra a conexão (C) entre a região mineralizada (RM) e o tecido conjuntivo (TC). Hematoxilina e Eosina.
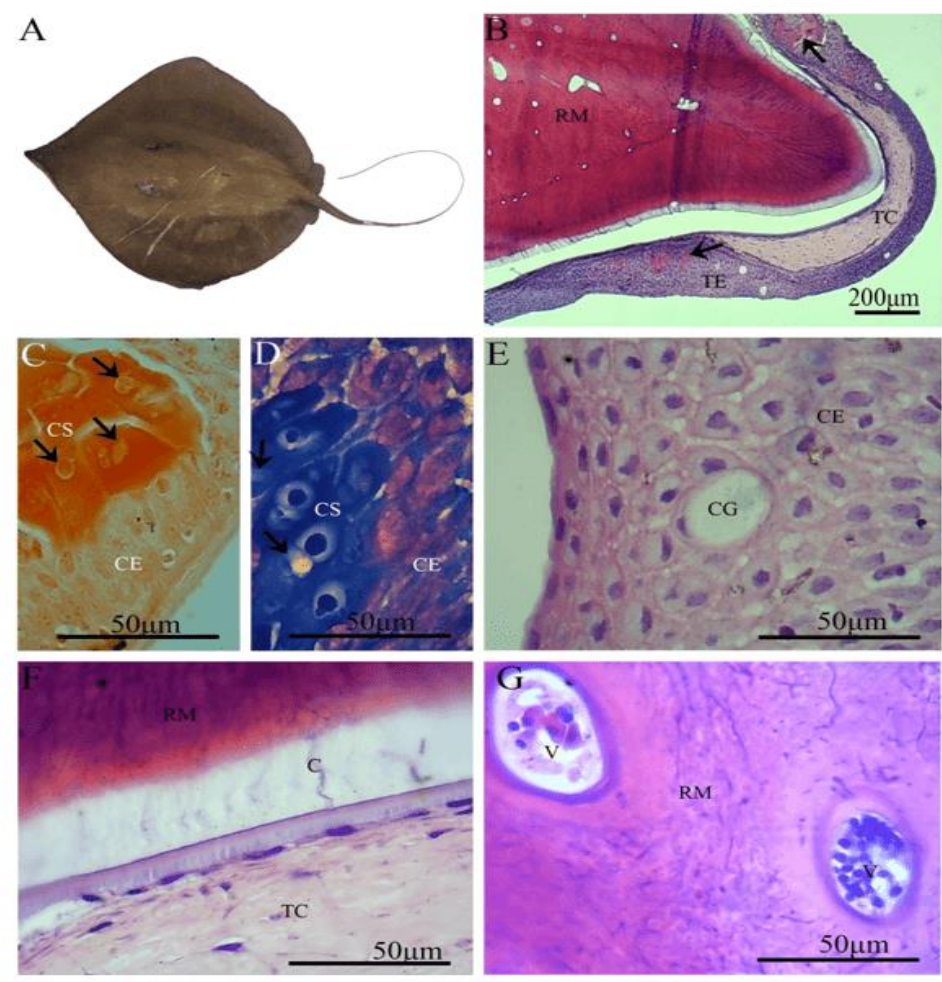

Fonte: autoria própria.

Os resultados demonstram que a estrutura do ferrão das espécies de água doce Potamotrygon orbignyi (Figura 3A) é composta por uma região óssea localizada no centro do ferrão, ao redor é encontrado o tecido conjuntivo e mais externamente uma 
cobertura de tecido epitelial (Figura 3B). O mesmo foi encontrado para Potamotrygon scobina e Plesiotrygon iwamae (Figuras 4B, 5B).

Em espécies de água doce, as células secretoras de veneno são alongadas, possuem vesículas fusiformes em seu citoplasma e armazenam material proteico (Figuras 3CD, 4C-D, 5C-D). As outras células do tecido epitelial que secretam muco têm uma forma mais arredondada e não armazenam conteúdo proteico (Figuras 3C-D, 4C-D, 5C-D). Outro tipo de célula comum nesses animais são as células glandulares que são descritas na literatura como células em forma de garrafa devido à sua forma alongada e possível conexão fora do epitélio (Figuras 3E, 4E, 5E). As células especializadas na produção de veneno em animais de água doce são distribuídas por todo o epitélio de revestimento do ferrão e não possuem região específica de concentração.

A região mineralizada é bastante vascularizada (Figuras $3 F, 4 F, 5 F$ ) contendo células e ainda possui forte conexão com o tecido conjuntivo (Figuras 3G, 4G, 5G). Também foi observado que o tecido conjuntivo é altamente vascularizado e possui hemácias nucleadas. 
Figura 3. Fotomicrografia da estrutura morfológica do ferrão de Potamotrygon orbignyi. A) Imagem da espécie Potamotrygon orbignyi. B) corte transversal do ferrão indicando a localização das células secretoras de veneno no tecido epitelial (TE). Tecido conjuntivo (TC) e região mineralizada (RM). Hematoxilina e Eosina. C) maior aumento do epitélio evidenciando as células secretoras de veneno (CS) vesícula das células secretoras de veneno (seta) e as células epiteliais (CE). Azul de Toluidina. D) maior aumento do epitélio evidenciando as células secretoras de veneno (CS), vesícula das células secretoras de veneno (seta) e as células epiteliais (CE). Xylidine Ponceau. E) corte evidenciando as células glandulares (CG). Vesículas das células secretoras de veneno (seta) e Células epiteliais (CE). Hematoxilina e Eosina. F) Imagem em maior aumento da região mineralizada (RM). É possível observar estruturas semelhantes a vasos sanguíneos (V). Hematoxilina e Eosina. G) corte histológico que mostra a conexão (C) entre a região mineralizada (RM) e o tecido conjuntivo (TC). Hematoxilina e Eosina.

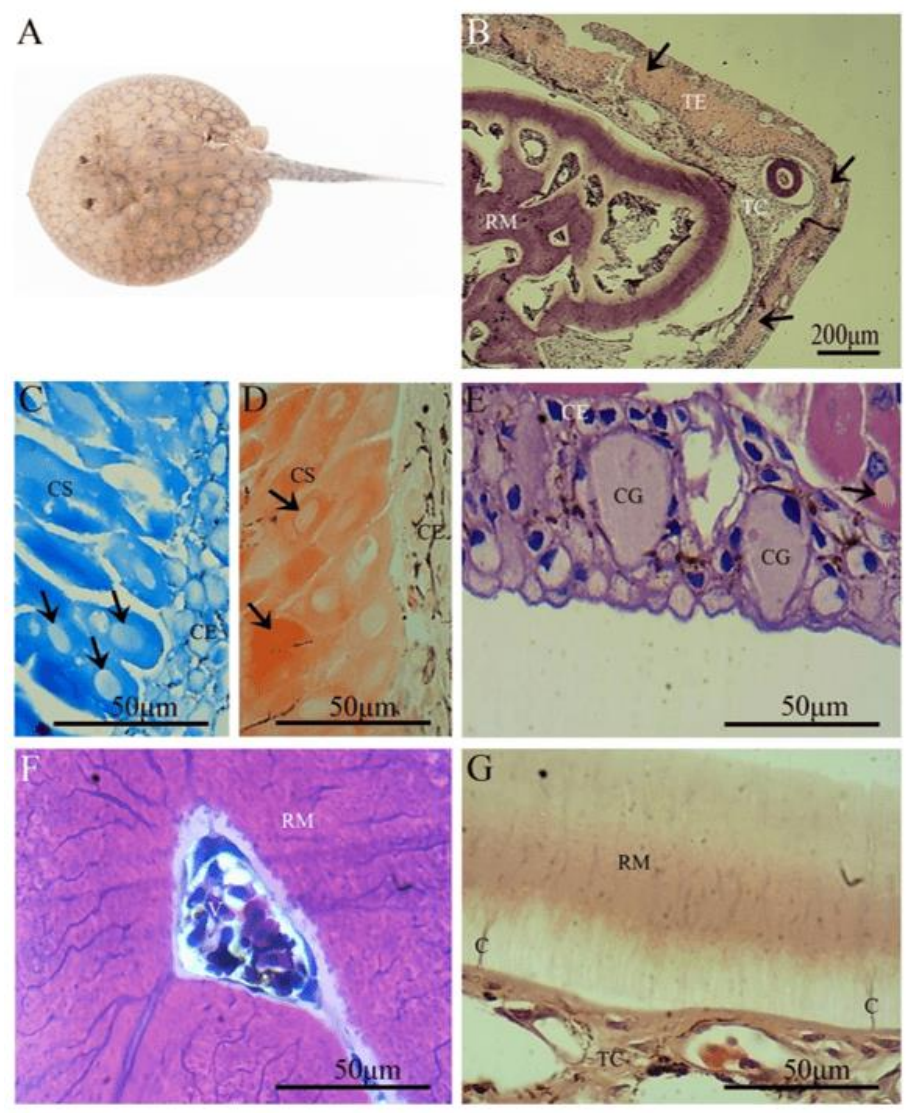

Fonte: autoria própria. 
Figura 4. Fotomicrografia da estrutura morfológica do ferrão de Potamotrygon scobina. A) Imagem da espécie Potamotrygon scobina. B) corte transversal do ferrão indicando a localização das células secretoras de veneno (seta) no tecido epitelial (TE). Tecido conjuntivo (TC) e região mineralizada (RM). Hematoxilina e Eosina. C) maior aumento do epitélio evidenciando as células secretoras de veneno (CS) e as células epiteliais (CE). Azul de Toluidina. D) maior aumento do epitélio evidenciando as células secretoras de veneno (CS), vesícula das células secretoras de veneno (seta) e as células epiteliais (CE). Xylidine Ponceau. E) corte evidenciando as células glandulares (CG). Vesículas das células secretoras de veneno (seta) e Células epiteliais (CE). Hematoxilina e Eosina. F) maior aumento da região mineralizada (RM). Sendo possível observar estruturas semelhantes a vasos sanguíneos (V). Hematoxilina e Eosina. G) corte histológico que mostra a conexão (C) entre a região mineralizada (RM) e o tecido conjuntivo (TC). Hematoxilina e Eosina.
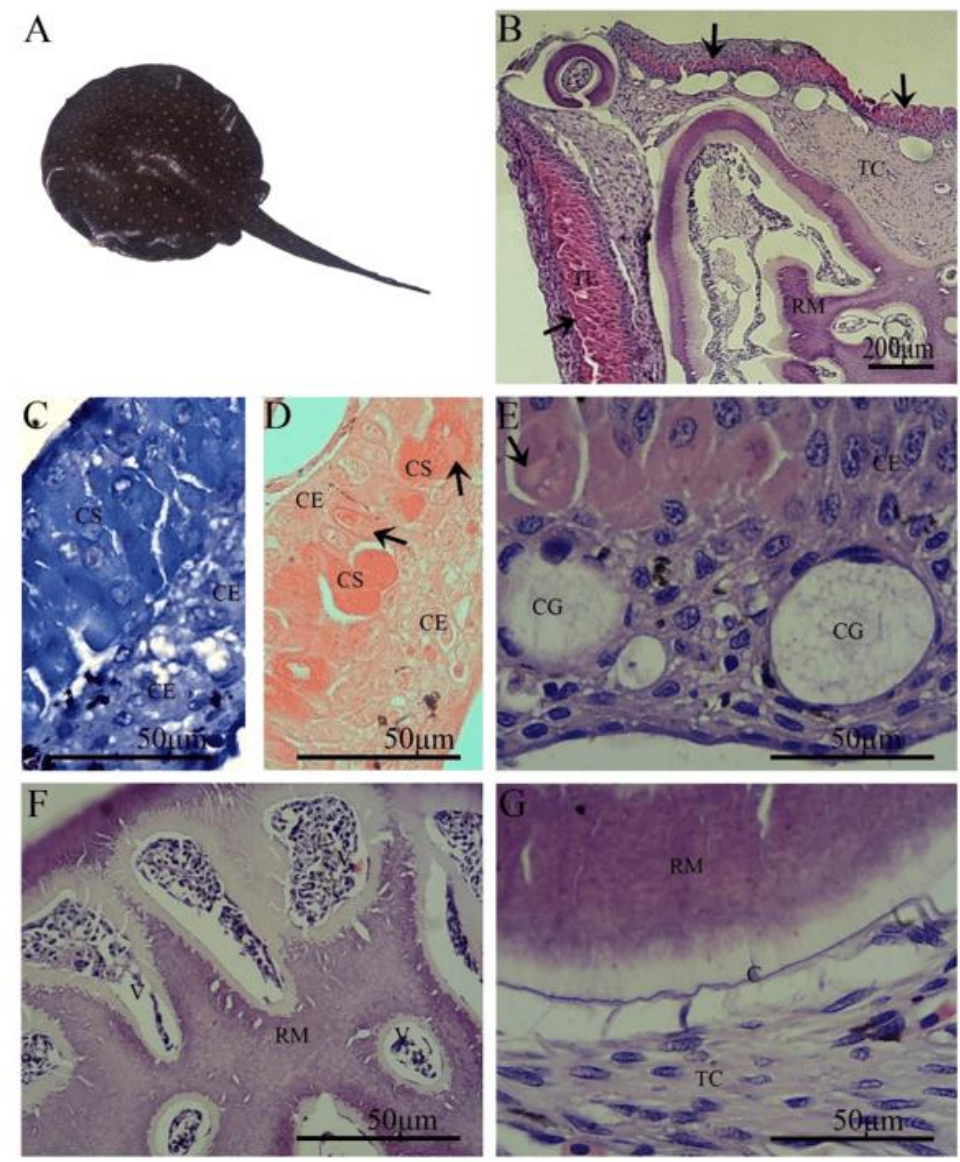

Fonte: autoria própria. 
Figura 5. Fotomicrografia da estrutura morfológica do ferrão de Plesiotrygon iwamae. A) Imagem da espécie Plesiotrygon iwamae. B) corte transversal do ferrão indicando a localização das células secretoras de veneno (seta) no tecido epitelial (TE). Tecido conjuntivo (TC) e região mineralizada (RM). Hematoxilina e Eosina. C) maior aumento do epitélio evidenciando as células secretoras de veneno (CS) e as células epiteliais (CE). Azul de Toluidina. D) maior aumento do epitélio evidenciando as células secretoras de veneno (CS), células glandulares (CG) e as células epiteliais (CE). Xylidine Ponceau. E) corte evidenciando as células glandulares (CG) e as Células epiteliais (CE). Hematoxilina e Eosina. F) maior ampliação da região mineralizada (RM). Sendo possível observar estruturas semelhantes a vasos sanguíneos (V). Hematoxilina e Eosina. G) corte histológico que mostra a conexão (C) entre a região mineralizada $(\mathrm{RM})$ e o tecido conjuntivo (TC). Hematoxilina e Eosina.

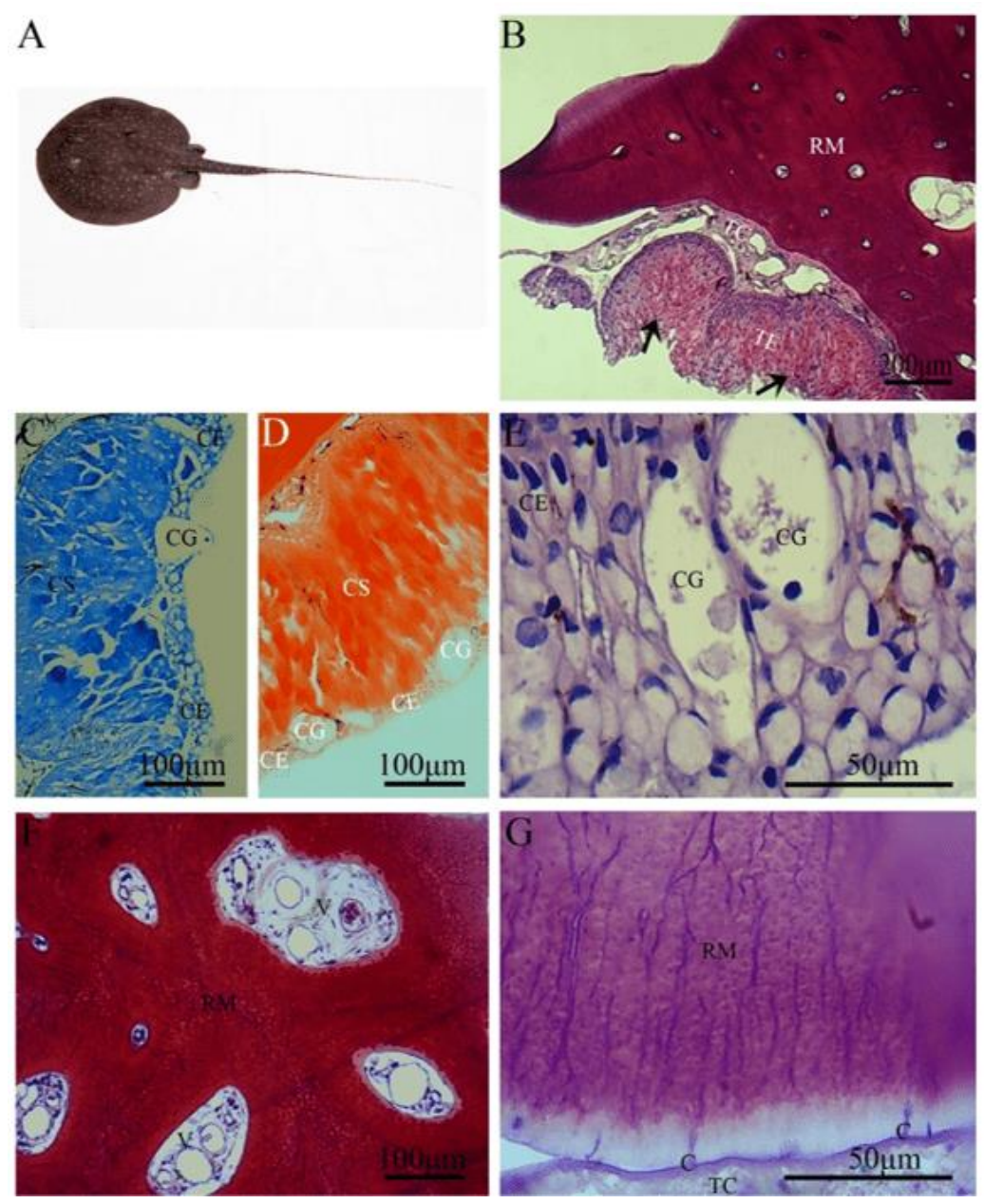

Fonte: autoria própria. 


\subsection{RESULTADOS HISTOQUÍMICOS}

Reações histoquímicas indicaram que as células secretoras de veneno, presente no epitélio dos ferrões, respondem positivamente ao corante XP evidenciando a presença de proteínas totais (Figs. 2C, 3D, 4D, 5D). Além disso, o citoplasma das células apresentou positividade ao corante AT o que indica a presença de açúcares ácidos (Figs. 2D, 3C, 4C, 5C).

\section{DISCUSSÃO}

As espécies Dasyatis guttata, Potamotrygon orbignyi, Potamotrygon scobina e Plesiotrygon iwamae apresentam ferrão com organização celular semelhante, isto é, todas elas possuem uma região mineralizada no centro ligado ao tecido conjuntivo que externamente está associado a um epitélio.

Em animais de água salgada as células especializadas na produção de veneno se localizam próximo às serrilhas laterais e formam agregados (DEHGHANI et al., 2010). Já nas espécies dulcícolas há uma distribuição das células secretoras de veneno por toda a extensão do epitélio. Ambas as espécies apresentam vesículas no interior das células de formato fusiforme e também possuem substâncias proteicas evidenciadas pela reação positivamente quando submetidas ao corante Azul de Bromofenol (DEHGHANI et al., 2010; PEDROSO et al., 2007).

De fato, essas células apresentam essa morfologia e são ricas em conteúdo proteico como foi evidenciado pelo corante XP na presente pesquisa. Segundo Russell (1965) componentes presentes no veneno da raia Urolophus halleri seriam a Serotonina, 5 nucleotidase e Fosfodiesterase identificados a partir de estudos com eletroforese. Além das proteínas podemos dizer que outro constituinte das células especializadas são os açúcares ácidos, visto que, quando submetidas á coloração com o AT reagiram positivamente. No entanto, não foi possível caracterizar essas moléculas nem mesmo estabelecer a atividade metabólica de proteínas e açúcares, um passo importante para a compressão dos mecanismos de funcionamento do veneno nos processos inflamatórios. Estudo que deve ser realizado em pesquisas futuras. 
As raias fluviais e marinhas possuem células epiteliais não especializadas na produção de veneno, que possuem um formato arredondado e são caracterizadas como células de muco que contêm muitos grânulos de secreção em seu citoplasma (DEHGHANI et al., 2010 ; PEDROSO et al., 2007). Nas análises microscópicas foi possível observar que esses grânulos se encontram também no espaço extracelular.

Acredita-se que as células produtoras de muco presentes no epitélio dos peixes possuem diversas funções como a locomoção do animal, pois diminui o atrito com a água o que pode gerar redução dos gastos de energia (SHEPHARD, 1994). Estudos realizados com muco da raia Hypanus americanus demonstraram atividade antimicrobiana contra o fungo Candida albicans. Além disso, ao ser injetado na pata de camundongos foi possível observar uma forte ação inflamatória e o aparecimento de edema que estão relacionados à ação de peptidases e peptídeos derivados de proteínas (COELHO et al., 2019).

Outro tipo celular bastante frequente no epitélio que recobre o ferrão desses animais são as células glandulares que foram descritas como células garrafais por apresentarem um formato alongado e uma conexão para fora do epitélio, mas em geral são células grandes que contem proteína hialina e só foram descritas por Pedroso et al. (2007) em animais dulcícolas no entanto, essas células podem conter um formato arredondado e conter açucares em sua composição, esse mesmo tipo celular também foi encontrado na espécie Dasyatis guttata.

Poucos autores descrevem a região óssea do ferrão, Pedroso et al. (2007) apenas cita ser uma região mineralizada. No entanto, foi possível identificar que tanto animais marinhos quantos animais dulcícolas possuem estruturas semelhantes a vasos sanguíneos na porção central da região mineralizada provavelmente auxiliando na manutenção geral do ferrão. Além disso, a região óssea possui conexão com o tecido conjuntivo evidenciando que apesar do tecido epitelial ser um tecido relativamente frágil existe uma região que liga fortemente o tecido conjuntivo á região óssea.

Os diferentes graus de gravidade dos acidentes envolvendo animais de água doce e marinha pode ser explicada pela ampla distribuição do veneno no epitélio (nas de 
água doce), enquanto em animais marinhos se encontra restrito a regiões especificas (PEDROSO et al., 2007).

No caso das raias de água doce as células secretoras de veneno se distribuem estrategicamente por todo o epitélio, o que demonstra uma estratégia de defesa diferente das raias marinhas que possuem células de veneno somente próximo às estruturas em forma de serra do ferrão. Isso pode estar relacionado aos ambientes onde esses animais habitam. Pois a família Potamotrygonidae ao se diversificar em águas da América do sul teve que desenvolver adaptações para o ambiente dulcícola (THORSON, 1967).

Contudo, outros fatores devem ser levados em consideração para determinação da gravidade do acidente. Já que pode ocorrer diferença na toxicidade entre as diferentes espécies de raias, que podem ainda estar relacionadas à maturidade sexual e o sexo do animal (SANTOS et al., 2019).

\section{CONSIDERAÇÕES FINAIS}

Dessa forma podemos dizer que é difícil avaliar a gravidade dos acidentes com raias de água doce ou salgada somente considerando a quantidade e posição das células de veneno. Pois como foi dito, outros fatores podem influenciar. No entanto, é notório que todos os animais estudados têm um padrão morfológico semelhante de ferrão apesar de suas peculiaridades e que na região de Soure a maioria dos acidentes está provavelmente relacionada a animais de água doce uma vez que a maioria das espécies capturadas foi dulcícola.

\section{REFERÊNCIAS BIBLIOGRÁFICAS}

ANTONIAZZI, Marta M.; BENVENUTI, L. A.; LIRA, M. S.; JARED, S. G. S.; NETO, D. G.; JARED, C., \& BARBARO, K. C. Histopathological changes induced by extracts from the tissue covering the stingers of Potamotrygon falkneri freshwater stingrays. Toxicon, v. 57, n. 2, p. 297-303, 2011. 
CARVALHO, MR de; LOVEJOY, N. R.; Rosa, R. S. Family Potamotrygonidae (river stingrays). Check list of the freshwater fishes of South and Central America, $p$. 22-28, 2003.

CHARVET-ALMEIDA, P.; ARAÚJO, M. L. G.; ROSA, R. S. \& RINCÓN, G. Neotropical freshwater stingrays: diversity and conservation status. Shark News, v. 14, p. 4751, 2002.

COELHO, Guilherme Rabelo; NETO, Pedro Prezotto; BARBOSA, Fernanda Cortinhas; SANTOS, Rafael Silva Dos; BRIGATTE, Patrícia; SPENCER, Patrick Jack; SAMPAIO, Sandra Coccuzzo; D'Amélio, Fernanda; PIMENTA, Daniel Carvalho; SCIANI, Juliana Mozer. Biochemical and biological characterization of the Hypanus americanus mucus: A perspective on stingray immunity and toxins. Fish \& shellfish immunology, v. 93, p. 832-840, 2019.

DEHGHANI, Hadi; SAJJADI, Mir Masoud; PARTO, Paria; RAJAIAN, Hamid; MOKHLESI, Amin. Histological characterization of the special venom secretory cells in the stinger of rays in the northern waters of Persian Gulf and Oman Sea. Toxicon, v. 55, n. 6, p. 1188-1194, 2010.

FUNASA. Manual de Diagnóstico e Tratamento de Acidentes por Animais Peçonhentos. Ministério da Saúde. v. 2, p. 120, 2001.

GARRONE NETO, Domingos; HADDAD JUNIOR, Vidal. Arraias em rios da região Sudeste do Brasil: locais de ocorrência e impactos sobre a população. Revista da Sociedade Brasileira de Medicina Tropical, v. 43, n. 1, p. 82-88, 2010.

GOMES, Ulisses Leite; SIGNORI, Camila Negrão; GADIG, Otto Bismarck Fazzano; SANTOS, Hugo Ricardo Secioso. Guia para identificação de tubarões e raias do Rio de Janeiro. Technical Books, Rio de Janeiro, 2010.

LASSO, C. A., R. S. ROSA, P. SÁNCHEZ-DUARTE, M. A. MORALES-BETANCOURT y E. AGUDELO-CÓRDOBA (Editores). IX. Rayas de agua dulce (Potamotrygonidae) de Suramérica Parte I: Colombia, Venezuela, Ecuador, Perú, 
Brasil, Guyana, Surinam y Guayana Francesa: diversidad, bioecología, uso y conservación. 2013.

LOVEJOY, Nathan R. Systematics of myliobatoid elasmobranchs: with emphasis on the phylogeny and historical biogeography of neotropical freshwater stingrays (Potamotrygonidae: Rajiformes). Zoological Journal of the Linnean Society, v. 117, n. 3, p. 207-257, 1996.

PEDROSO, Catia M; JARED, C.; ChARVET-AlmeidA, P.; AlMeIDA, M. P.; GARRONE NETO, D.; Lira, M. S.; HADDAD Jr., V.; BARBARO, K.C.; ANTONIAZZI, $M$. M. Morphological characterization of the venom secretory epidermal cells in the stinger of marine and freshwater stingrays. Toxicon, v. 50, n. 5, p. 688-697, 2007.

ROSA, Ricardo de Souza. A systematic revision of the South American freshwater stingrays (Chondrichthyes: Potamotrygonidae). Unpublished Ph. D. Dissertation. The College of William and Mary, Williamsburg, Virginia, pp. 523, 1985.

RUSSELL, Findlay E. Marine toxins and venomous and poisonous marine animals. In: Advances in marine biology. Academic Press, 1965. p. 255-384.

SAMPAIO, Wagner Martins Santana. Arraias de Água Doce: Potamotrygon (Myliobatiformes : Potamotrygonidade). Fauna Neotropoical 1, 14-17, 2014.

SANTOS, Juliane Monteiro dos; SANTOS, Janaína Cardoso dos; MARQUES, Elineide Eugênio; ARAÚJO , Gessi Carvalho de; SEIBERT, Carla Simone; LOPES-FERREIRA, Mônica; LIMA, Carla. Stingray (Potamotrygon rex) maturity is associated with inflammatory capacity of the venom. Toxicon, v. 163, p. 74-83, 2019.

SHEPHARD, Kerry L. Functions for fish mucus. Reviews in fish biology and fisheries, v. 4, n. 4, p. 401-429, 1994.

THORSON, Thomas B. Osmoregulation in fresh-water elasmobranchs. John Hopkins University Press, Baltimore. p.265,1967. 


\section{ANEXO}

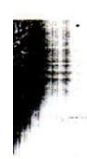

Oficio $n^{\circ} 187 / 2019$

PREFEITURA MUNICIPAL DE

SOURE

SECRETARIA MUNICIPAL DE

SAÚDE

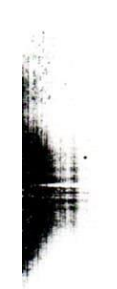

Soure/Pá 18 de Outubro de 2019

Da: Secretaria Municipal de Saúde de Soure/Hospital Menino Deus Para: Universidade Federal do Para

Assunto: Resposta a Solicitação de registros de acidentes com raias.

Prezado (a) Senhor (a)

Com os nossos cordiais cumprimentos, através do presente estamos encaminhando a resposta ao OF. $\mathrm{n}^{\circ} 01 / 2019-\mathrm{LBCM}$, de acordo com nossos registros no ano de 2018 tivemos um total de 93 acidentes com raias, e no ano de 2019 até o mês de Setembro foram registrados 62 acidentes.

No ensejo, renovamos votos de elevada estima e consideração.

Cordialmente,

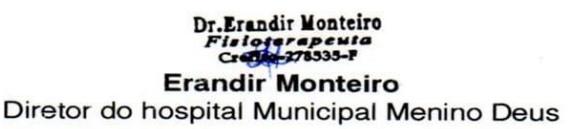

Diretor do hospital Municipal Menino Deus

2. Rua, s/ne , Centro, CGC 05.133.863.001/50, Fone: 3741 1275, Soure - Pará - Brasil

Enviado: Julho, 2020.

Aprovado: Outubro, 2020.

RC: 63285

Disponível em: https://www.nucleodoconhecimento.com.br/biologia/analise-histologica 